Borneo Journal of Sciences \& Technology, 4(1): 70-79

DOI: http://doi.org/10.3570/bjost.2022.4.1-11

e-ISSN: 2672-7439

(C) 2018, UTS Publisher.

Submitted: $01^{\text {st }}$ December $2021 \quad$ Accepted: $17^{\text {th }}$ January $2022 \quad$ Published: $31^{\text {st }}$ January 2022

\title{
A Review of Internet of Things Application in Malaysia
}

\author{
${ }^{1,2}$ Suman Tiwari \\ ${ }^{1}$ School of Business and Management, University of Technology Sarawak, \\ 96000 Sibu, Sarawak, Malaysia \\ ${ }^{2}$ Faculty of Technology Management and Business, Universiti Tun Hussein Onn Malaysia, \\ Batu Pahat, Malaysia
}

\begin{abstract}
Smart and Internet of Things (IoT) technology' fast growth and application has produced new opportunities for technological advancements in a wide variety of areas. The fundamental objective of IoT technology is to optimise operations across a wide variety of sectors, to boost system efficiency (via technology or specialised activities), and to ultimately improve living quality. While the fast rise of IoT technology provides several beneficial benefits, this rapid growth must be adequately monitored and analysed from an environmental perspective in order to minimise negative consequences. Malaysia is one of the nations that are in the planning stages of increasing IoT applications, which is comparable to other countries experiencing rapid IoT growth. This article discusses the latest breakthroughs and uses of the Internet of Things in Malaysia. Additionally, it examines current IoT applications and implementations in a variety of sectors, including manufacturing, agriculture, education, healthcare, smart cities, and transportation. The future developments and uses of IoT also were discussed in this article in order to have a better grasp of the technology. The review article's key conclusions aided in a better understanding of current technological advancements in IoT applications.
\end{abstract}

Keywords: Internet of Things (IoT), manufacturing, smart city, transportation

\section{INTRODUCTION}

With the advancement of technology in society, new opportunities are rising that have the potential to simplify our everyday lives and deliver more efficient services or industrial processes. "Smart" has become the epicentre of an ongoing technical breakthroughs as a result of digitalisation [1]. In fact, IoT technologies are increasingly regarded as one of the foundations of the fourth industrial revolution, owing to their great potential for innovation and societal benefits. Internet of things (IoT)-based technologies provide a whole new viewpoint on the future advancement of numerous areas, such as engineering [2], agriculture [3], or medical [4]. Some prospective application areas in IoT technologies are currently unknown or insufficiently clear on how to approach them, indicating that more intensive research effort in economic sector should be done in order to achieve new and significant potential advantages for society. As a result, the significance and value of IoT technologies in the future are more than evident, and they should play a significant role. There are several sophisticated technologies on the market now that are directly linked to the Internet. The number of gadgets continues to grow in tandem with technological advancements.

IoT refers to a connected device that permits connection with other devices, after which data is taken and processed into useful and relevant information [59]. RFID, remote wireless communication, real-time localisation, and sensor networks are examples of IoT technology. Smartphones, tablets, and laptops are examples of smart gadgets and technology that are also considered components of the IoT [10]. With IoT technologies, as many as linked devices may be used to aid the report in order to record the identification and position via wired or wireless connections [11]. The term "Internet of Things" refers to everything that has to do with computers, software, and the internet. Many technologies are used to run a company, including any road or network to go to anywhere as soon as possible, anywhere and everywhere to access or utilise technology, and anything and everything that has an intelligent system built into it. As a part of the Internet of Things, these devices are integrated to communicate and connect with people.

The growth of IoT has captured attention and has been acknowledged as an innovative future technology that is receiving interest from numerous areas around 


\section{A Review of Internet of Things Application in Malaysia}

the country [12]. Because it is a country in Southeast Asia, Malaysia has the necessary infrastructure for IoT acceptance. IoT was widely introduced across Malaysia in 2015, according to the country's authorities. Based on Malaysia's strategic and structural backdrop, it may be a good place to start for the growth of IOT in the domestic market. Malaysia has been ranked fourth in the United Nations E-Government Commission's 2015 Online Services Index as the top digital economy in developing countries [13].

The Internet of Things (IoT) is gaining traction in Malaysia for a variety of reasons. Figure 1 shows the Internet of Things application in the years to come (up to 2025). More than 150 percent of Malaysians already own a smartphone, and that figure is anticipated to rise to 280 percent by 2025 . More than 59 percent of Malaysian Internet users download mobile applications, compared to the Southeast Asian average of 67 percent [14], driving the country's Internet usage growth dramatically to a whopping 190 percent by 2025. This is mostly due to active online behaviour. The number of people with access to broadband in Malaysia is expected to rise to 170 percent by 2025 , thanks to an increase in the number of people signing up for the service. Mobile Malaysia, Ahead of the Pack's One Device survey found that Malaysians spend an average of $\$ 2,000$ on online transactions each year. In contrast, 75 percent of Malaysians are active on social networking sites, making it the most widely used form of social media in the country. In general, Malaysia will become a more conducive environment for IOT implementation as mobile devices and the Internet become more widely available [15].

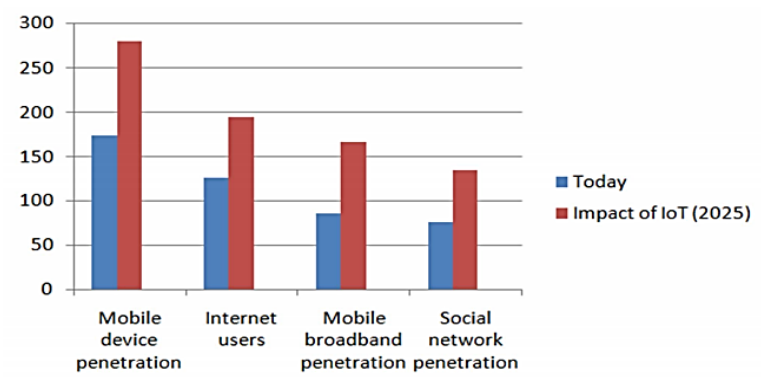

Figure 1: IoT application in Malaysia

IoT technology research has been on the rise in recent years, according to a number of studies that have been published. IoT solutions will be essential to maintain cities' regular operations in the face of these complicated and demanding circumstances, since increased urbanisation will place a huge strain on their infrastructure [47]. Malaysia is still slow in taking full advantage of the digital transformation compared to other neighbouring countries like Singapore and Vietnam. For instance, overall there are only 21 percent of manufacturers who adopt IoT to improve the business processes [78]. Nevertheless, it is essential to research on current IoT application as this field is undergoing innovative positive improvements [48]. Therefore, this study examines the most current advancements and applications of IoT. It also explore the present applications of IoT in manufacturing, agriculture, education, healthcare, smart city and transportation. Finally, this article evaluates the future orientations of IoT implementation in Malaysia. Industrial practitioners as well as academician will be benefited from this study's findings, and it contributes to a deeper knowledge and awareness of Internet of Things (IoT) applications, technical possibilities, and Malaysia's continuous adoption of IoT application. Comprehensive reviews were conducted in order to meet the objective of this article.

\section{IOT APPLICATION IN MALAYSIA}

Malaysia is well-positioned to reap the benefits of the Internet of Things' economic potential. Wireless broadband and cellular penetration rates in the EandE industry are 67 percent and 145 percent, respectively [16]. IoT efforts will be enabled by the establishment of small and medium-sized businesses (SMEs) that have solid foundations and undertake several government-led innovation projects [16]. To achieve Malaysia's objective of becoming the leading regional IoT development hub, the National IoT Roadmap aspires to create a national ecosystem that will facilitate the broad acceptance and industrialisation of the Internet of Things as a new source of growth for the Malaysian economy.

Malaysia's gross national income is expected to rise from RM9.5 billion in 2020 to RM42.5 billion in 2025 as a result of the Internet of Things business. The National IoT Strategic Roadmap has three key objectives [16]: i) develop Malaysia as the premier regional IoT development hub; (ii) create a favourable IoT industrial environment to facilitate the seamless application of IoT technology; and (iii) strengthen technopreneur talents and capacities in apps and services creation using IoT technology. The goal of encouraging the development of IoT in Malaysia is to improve the quality of life via the use of ICT applications. The highly targetted industries for IoT application in Malaysia include manufacturing, agriculture, education, healthcare, smart city, and transportation.

\section{IOT AND MANUFACTURING}

The adoption of IoT technology in industrial applications will boost production efficiency and enable improved communication and networking capabilities between humans and machines [57]. It would help enterprises to be more competitive on the market by 


\section{A Review of Internet of Things Application in Malaysia}

enhancing quality control. An important element would be the creation, design, and integration of a variety of relevant sensors for industrial applications [17], in order to create integrated and effective management systems. As a result of the IoT, manufacturing industries now have the ability to connect Radio Frequency Identification (RFID) tags to a wide range of items [61]. An increasing number of devices are being used to manage and track inventory, as well as enhancing customer service and reducing lead time.

Real-time data on operational conditions and the condition of spare parts are gathered via sensors installed in machinery and equipment. For further processing, this data are transmitted to a cloud computing platform [51]. Finally, the findings are shown in a user application, giving shop floor supervisors a comprehensive picture of the manufacturing process. IoT technology providing a high level of operational transparency which was never possible. It is now feasible to continually monitor production conditions and make data-driven choices in real time to maintain equipment functionality as well as enhance product quality [56]. Additional study is required to ensure the proper implementation of IoT technologies in industry and to gain a deeper understanding of how IoT technologies may be deployed in specific industries where advantages could be realised. There is a necessity in connecting numerous industrial sensors, using and processing the resulting data to allow better industrial processes, such as smart IoT-based Computer-Integrated Manufacturing [18].

\section{IOT AND AGRICULTURE}

A developing idea, "smart farming" refers to the management of farms employing IoT, robots, drones, and artificial intelligence (AI) in order to boost production quantity and quality while optimising human labour [67]. Connected smart tools and sensors integrated on farms are what the Internet of Things (IoT) means in Smart Farming technology [68]. IoT technologies are necessary in agriculture for managing agricultural operations. Agriculture production efficiency is critical for our people to avoid a future food shortage caused by a variety of circumstances [19]. As previously said, the first element is continual population expansion; the second is related to climate change difficulties [20], which is resulting in a decrease in the yields of critical crops, or in certain places becoming unsuitable for effective agriculture production.

IoT is critical for agriculture. For instance, an IoT-enabled smart agricultural system was integrated with an irrigation system in order to deal with Malaysia's inconsistent weather [92]. This system's microcontroller is a Raspberry $\mathrm{Pi} 4$ Model B. The
DHT22 and soil moisture sensor are used to detect the ambient temperature and humidity, as well as the soil moisture level, respectively, with the result displayed on the smartphone and computer [93-95]. Thus, Smart Agriculture Systems powered by the Internet of Things and Raspberry Pi have a profound effect on the way farmers work [96-97]. Additionally, it will have a beneficial influence on Malaysia's agriculture productivity. Where a water savings rate of around 24.44 percent per year may be realised when implementing IoT-based irrigation systems vs traditional irrigation systems [92]. This will save money on labour costs and prevent water loss during regular activities [98-100].

Food waste is a big concern [21], since it has become a global issue, particularly in industrialised nations. Over 28 percent of potential agricultural land is projected to be "reserved" for food waste [22]. Implementing IoT technology in agriculture may undoubtedly contribute to ensuring enough food supply and increasing the efficiency of agricultural production operations in general [69]. Malaysia's agricultural goal is to place an emphasis on food capability by enhancing Malaysia's reputation for food quality and as a Halal centre [71].

\section{IOT AND EDUCATION}

Malaysia intends to create and share innovative methodologies, reference data and materials, testing methods, other infrastructure, and technological services necessary by Malaysia's IOT industry to maintain its competitiveness. Today, Malaysia has developed and implemented a new learning approach known as Massive Open Online Courses, which promotes the use of open learning (MOOC) [23]. This learning technique allows everyone in the community to access the open learning source at any time and from any location, as well as exchange information with one another. Malaysia's academic goal is to support lifelong learning by creating a favourable learning environment [49].

After the emergence of Covid-19 pandemic, the necessity of Smart Digital Campus for the learning and administrative processes at higher education institutions has been increasingly popular [62]. Teaching, learning, and research may all be improved by incorporating cutting-edge technology into the physical infrastructure [63]. Smart Digital Campus can cut operating expenses, increase security, and provide digital capabilities for students and faculty member [64]. Using IoT devices and the IT service delivery platform to link the whole digital campus, it was claimed that a "Smart Digital Campus" may improve student learning and administration by combining these two components [65]. A digital campus should consist of five primary categories: i) Building Control and Management; ii) 


\section{A Review of Internet of Things Application in Malaysia}

Security and Access Control; iii) Video and Information Systems; iv) Location Attendance Systems, and v) Energy Monitoring and Control [66].

The Internet of Things is rapidly expanding throughout the world. The true value of IoT is realised through the integration of objects and knowledge in decision-making, which will be implemented into business, the personal environment, and our society [50]. Despite admitting the enormous potential of IOT, various obstacles must be posed. Every country that begins IoT deployment has concerns and hurdles in maintaining IoT operability. Malaysia conceals the same challenges in order to attain IOT growth. A few major concerns were briefly discussed. The key difficulty for the development of IoT technology in Malaysia is the integration of diverse network technologies in public IP networks to enable scalable and reliable network connection [24]. With the increased adoption of IoT technology, each industry must analyse its networking aspects to enable optimal data transfer across wired and wireless networks. For Future Internet architecture, IOT relies on connection and dependability to communicate [25].

\section{IOT AND HEALTHCARE}

The healthcare system has been designated as a tough deployment arena for IoT technology through the ehealth concept [26]. Patients' life expectancy might be increased through better patient safety and care as a consequence of enhanced IoT support (mainly the collection of patient health data) in the healthcare system. In addition to measuring vital human functions like heart rate, skin temperature, and movement [27], there is enormous potential for smart medical devices to be utilised for a wide range of other purposes as well. Another exciting potential is the implementation of remote health monitoring through the use of IoT devices and commodities.

Generally, it may be feasible to forecast many symptoms and avert potentially deadly disorders and [28]. A patient's general health and nutrition status could also be monitored continuously using IoT devices, which could help the elderly [29]. The healthcare business is making extensive use of the IoT. Use this app to improve your quality of life and contribute to a healthier lifestyle in healthy and wellness. Smart medical sensors, for example, will be provided to every patient in order to keep tabs on vital signs like temperature, blood pressure, and even breathing [60]. There are a variety of other sensors available, including wearable sensors. Data collected by this sensor may be categorised according to how it monitors the patient's lifestyle and environment [30]. The goal of Malaysia's healthcare system is to promote healthy living and wellness by expanding the provision of health care services at all times and places.

\section{IOT AND SMART CITY}

The involvement of IoT technologies in the smart city idea is critical for bridging the previously described worldwide infrastructure issues in cities, which are directly related to the present population growth [31]. IoT technologies in smart cities will enable the use of various devices, hence improving urban living quality and the efficiency of many everyday activities such as transportation, security (surveillance), smart metering, smart energy systems, and smart water management, among others. Numerous sensing devices would collect data, which would be analysed in order to produce efficient and beneficial solutions.

The primary benefit of IoT technology in smart cities would be the early identification of various problems or infrastructure failures (such as traffic congestion, electricity supply, water scarcity, and security events) [52]. In smart cities, several sensors are deployed and connected to numerous other devices through the internet, providing users with information on parking places, malfunctions, electrical failures, and a variety of other issues [53]. The Smart City Framework Malaysia (MSCF) is a national-level framework that provides direction and reference for Local Authorities as city managers, state governments, federal ministries and agencies, industry stakeholders, educators, and other stakeholders in planning and developing smart cities holistically and in line with current developments in Malaysia [16]. The document defines smart cities in the context of Malaysia, specifies their seven critical components, policy orientations, and proposes strategies and initiatives for each component, which can serve as a guide for anyone interested in developing smart city projects in Malaysia.

The MSCF was designed with the development and implementation of smart cities in Malaysia in mind [72]. The Malaysian government believes that smart cities are the future approach to urban planning, development, and management because they can address urban challenges such as inefficient service delivery, environmental pollution, and traffic congestion, thereby improving urban residents' quality of life [73]. Additionally, the MSCF was founded to address national and global priorities, particularly those related to attaining the Sustainable Development Goals (SDGs) and ensuring that Malaysia remains current with global urban development trends [74]. In Malaysia, a smart city is described as 'a city that leverages ICT and technological advancements to address urban concerns, such as improving residents' quality of life, promoting economic growth, developing a sustainable and safe environment, and encouraging efficient urban management practices [16]. Malaysia's smart city initiative intends to address urban concerns and challenges in order to achieve the three pillars of a 


\section{A Review of Internet of Things Application in Malaysia}

competitive economy, a sustainable environment, and an improved quality of life [75].

The seven key components of Malaysia's smart city are as follows: i) Smart Economy; ii) Smart Living iii) Smart Environment; iv) Smart People v) Smart Government vi) Smart Mobility; and vii) Smart Digital Infrastructure [70]. The most pressing implementation obstacles today are those related to the efficient integration of various sensing technologies, the construction of an appropriate network infrastructure, population education, and an examination of sustainability issues such as carbon footprint. Within the context of the smart city idea, the deployment of IoT technology in smart homes [32] enables efficient integration of renewable energy technologies in homes [33].

\section{IOT AND TRANSPORTATION}

Transportation modes will undergo substantial changes in the future decades, [34], most notably due to the anticipated increased market penetration of electric vehicles, [35]. The impending phase-out of dieselpowered vehicles due to environmental concerns [36] and the subsequent development of alternative transportation technologies, such as hydrogen-powered vehicles [37] will significantly alter the shape of future transportation systems. In general, there is a desire for more ecologically friendly modes of transportation, which are now being developed progressively with the goal of market penetration. To enable desirable vehicle autonomy, a necessary expansion of transportation infrastructure is required.

Nowadays, the IoT has shown itself in the notion of the "internet of automobiles" [38], demonstrating its promise in this critical field. The most major Internet of Things application area is the notion of the smart automobile (vehicles) [39]. The smart car idea takes into account the usage and optimization of many internal operations within the vehicle, which are enabled by IoT technology. The use of IoT would enhance the driver experience and promote driver comfort and safety. The smart automobile collects specific data and associates it with key operational characteristics such as tyre pressure, fuel consumption, early detection of possible faults, and regular maintenance signs, among others [77]. In general, focused use of IoT technology can result in greater service and added value for consumers, which can ultimately result in increased competition amongst automotive manufacturers. The most difficult part of IoT implementation is when autonomous cars are involved [40].

The location, direction, and planned course of the autonomous vehicle may all be efficiently supported by IoT in general, as well as the monitoring of autonomous car safety systems [41]. The primary concern with autonomous cars is the prevention and avoidance of vehicle collisions, which might be addressed by the targeted use of IoT devices [42]. Smart parking is also one of the most rapidly growing IoT applications in the transportation industry in general. Numerous research efforts are made in that direction, with the primary objective of enabling the most up-to-date state of available parking spaces, as well as the control and monitoring of various important parking space information in real time [43].

Again, it is critical to create sensor technologies, such as smart parking sensors, in order to provide efficient and precise service [44]. According to Vicks Kanagasingam, former CEO of Xperanti, he stated that "We've deployed 12,000 parking sensors on Penang Island and 3,000 in Seberang Prai, with another 20,000 to be installed this year. It is designed to reduce traffic because you will know exactly where there are parking spaces before you leave the house." [58]. IoT might potentially be used to help the maintenance and failure prevention of various vehicles [45], hence increasing vehicle security and longevity. Taking all of the above into consideration, IoT technologies have the potential to significantly improve the driving experience and the overall quality of transportation networks [54]. IoT improves two-way communication, control, and data dissemination at every transport tier. Personal vehicles such as cars, commercial vehicles such as trains, UAVs, and other equipment are examples of these uses [46]. IoT technology span the whole transportation system, including traffic control, parking, fuel usage, and more [55]. Malaysia's transportation goal is to be one of the top five in Asia Pacific container and container trails. Malaysia also wants the opportunity to improve trade facilities and strengthen Malaysia's competitive edge in supply chain management methods [59]. E-parking, taxi reservations, bus transportation information, and, most significantly, travel and train information recommendations with real-time information for convenient travelling are all suggested apps [76].

\section{CONCLUSION}

The key contributions include an assessment of current trends in IoT deployment, a discussion of the advantages of the Internet of Things, and a description of the value of IoT to individuals as IoT users. Following that, the Internet of Things is being applied in a few industries, including manufacturing, agriculture, education, healthcare, smart cities, and transportation. Then, the future paths for IoT implementation in Malaysia were assessed. Malaysia has to develop a coherent national innovation plan to capitalise on the benefits of the Internet of Things and to help realise its vision of being a high-income economy objective [79]. The innovation of IoT has made it feasible for industries to upgrade their 


\section{A Review of Internet of Things Application in Malaysia}

traditional usage process [80]. Therefore, rather than launching new initiatives, Malaysia should focus on identifying essential industries that may become IoT domain members and maintain long-term competitiveness [81]. To be precise, Malaysia's innovation plan will succeed only if it is executed flawlessly through selected people, infrastructure, and the right sources [82]. Malaysian industry should embrace the utilisation of IoT application [83];[84];[85]. The industries or most dominated sector should engage in IoT research and development as well as staff training on the usage of IoT [86];[87]. Malaysian government could also integrate the implementation of IoT in school curriculums to promote the younger generation's interest at a very early level [88];[89];[90]. Malaysia has significant potential in being the market leader in Southeast Asia in terms of the IoT application [91]. With this, Malaysia can compete with the rest of the globe in terms of IoT's quick development and global expansion based on present achievements.

\section{REFERENCES}

[1] Zheng, C., Yuan, J., Zhu, L., Zhang, Y., Shao, Q., 2019. From digital to sustainable: a scientometric review of smart city literature between 1990 and 2019. J. Clean. Prod. 258.

[2] Zaidan, A.A., Zaidan, B.B., (2020). A review on intelligent process for smart home applications based on IoT: coherent taxonomy, motivation, open challenges, and recommendations. Artif. Intell. Rev. 53 (1).

[3] Farooq, M. S., Riaz, S., Abid, A., Umer, T., and Zikria, Y. B., 2020. Role of IoT technology in agriculture: A systematic literature review. Electronics, 9(2), 319.

[4] Salagare, S., Prasad, R., 2020. An overview of internet of dental things: new frontier in advanced dentistry. Wireless Pers. Commun. 110 (3), 13451371.

[5] I. Paper, 2011.The Web of Things: A Survey, vol. 6, no. 6, pp. 424-438.

[6] J. Mineraud, O. Mazhelis, X. Su, and S. Tarkoma 2016. A gap analysis of Internet-of-Things platforms, Comput. Commun., vol. 89-90, pp. 516.

[7] Y. Zhang and X. Wu., 2017. Access Control in the Internet of Things: A Survey.

[8] D. Singh and A. J. Jara., 2014. A survey of Internet-of-Things: Future Vision, Architecture, Challenges and Services, pp. 287-292.

[9] B. Torğul, L. Şağbanşua, and F. Balo., 2017. Internet of Things: A Survey Internet of Things: A Survey.

[10] A. J. Jara, L. Ladid, and A. Skarmeta., 2013. The Internet of Everything through IP6: An Analysis of
Challenges, Solutions, and Opportunities, J. Wirel. Mob. Networks, Ubiquitous Comput. Dependable Appl., 4(3), pp. 97-118.

[11] A. Kamilaris and A. Pitsillides., 2016. Mobile phone computing and the Internet of Things: a survey, IEEE Internet Things (on print), 3(6), pp. $1-13$.

[12] A. Al-fuqaha, M. Guizani, M. Mohammadi, M. Aledhari, and M. Ayyash., 2015. Internet of Things: A Survey on Enabling Technologies, Protocols and Applications Internet of Things: A Survey on Enabling Technologies, Protocols, and Applications, 17(1). pp. 2347-2376.

[13] National Internet of Things Strategic Roadmap., 2020. Retrieved from http://www.mimos.my/iot/National_IoT_Strategic_ Roadmap_Summary.pdf on December 2021

[14] R. H. Weber and E. Studer., 2016. Cybersecurity in the Internet of Things: Legal aspects, Comput. Law Secure. Rev., 32(5), pp. 715-728, 2016.

[15] S. Maharjan.,2010. RFID and IOT: An overview, Simula Res. Lab. Univ. Oslo.

[16] My Government., 2021. Malaysia Smart City Framework (MSCF). Retrieved from https://www.malaysia.gov.my/portal/content/30947 on December 2021

[17] Li, Y., Gao, M., Yang, L., Zhang, C., Zhang, B., and Zhao, X., 2020. Design of and research on industrial measuring devices based on Internet of Things technology. Ad Hoc Networks, 102, 102072.

[18] Chen, Y.-Q., Zhou, B., Zhang, M., Chen, C.-M., 2020. Using IoT technology for computerintegrated manufacturing systems in the semiconductor industry. Applied Soft Computing Journal 89. Article number 106065.

[19] Hussain, M., Butt, A.R., Uzma, F., Ahmed, R., Irshad, S., Rehman, A., Yousaf, B., 2020. A comprehensive review of climate change impacts, adaptation, and mitigation on environmental and natural calamities in Pakistan. Article number 48 Environ. Monit. Assess. 192 (1).

[20] Yang, M., Wang, G., Ahmed, K.F., Adugna, B., Eggen, M., Atsbeha, E., You, L., Koo, J., Anagnostou, E., 2020. The Role of Climate in the Trend and Variability of Ethiopia's Cereal Crop Yields, vol. 723. Article number 137893.

[21] Keng, Z. X., Chong, S., Ng, C. G., Ridzuan, N. I., Hanson, S., Pan, G. T., and Lam, H. L., 2020. Community-scale composting for food waste: A life-cycle assessment-supported case study. Journal of Cleaner Production, 261, 121220.

[22] Fao Org., 2020. Food and agriculture organization of the United Nations. Retrieved from fao.org/news/ story/en/item/196402/icode/, on December 2021. 


\section{A Review of Internet of Things Application in Malaysia}

[23] Open Learning., 2021. Retrieved from https://www.openlearning.com/pressreleases/Openl earningComSelectedAsMalaysiaSNationalMoocP1 atform/ on December 2021

[24] T. Guarda et al., 2017. Internet of Things challenges. 12th Iber. Conf. Inf. Syst. Technol., pp. $1-4$.

[25] H. Rahman and R. Rahmani., 2017. Enabling distributed intelligence assisted Future Internet of Things Controller (FITC), Appl. Comput. Informatics, pp. 1-15.

[26] Farahani, B., Barzegari, M., Aliee, F. S., and Shaik, K. A., 2020. Towards collaborative intelligent IoT eHealth: From device to fog, and cloud. Microprocessors and Microsystems, 72, 102938.

[27] Panteli, C., Kylili, A., and Fokaides, P. A., 2020. Building information modelling applications in smart buildings: From design to commissioning and beyond A critical review. Journal of Cleaner Production, 265, 121766.

[28] Muthu, B.A., Sivaparthipan, C.B., Manogaran, G., Sundarasekar, R., Kadry, S., Shanthini, A., Dasel, A., 2020. IOT based wearable sensor for diseases prediction and symptom analysis in healthcare sector.

[29] Nivetha, R., Preethi, S., Priyadharshini, P., Shunmugapriya, B., Paramasivan, B., and Naskath, J., 2020. Smart health monitoring system using iot for assisted living of senior and challenged people. International Journal of Scientific and Technology Research, 9(2), 4285-4288.

[30] N. Asghar, Mohsen Hallaj and Negi, Atul and Mohammadzadeh., 2015. Principle Application and Vision in Internet of Things (IoT), Int. Conf. Comput. Commun. Autom., pp. 427-431.

[31] Janik, A., Ryszko, A., and Szafraniec, M., 2020. Scientific landscape of smart and sustainable cities literature: A bibliometric analysis. Sustainability, 12(3), 779.

[32] Moniruzzaman, M., Khezr, S., Yassine, A., and Benlamri, R., 2020. Blockchain for smart homes: Review of current trends and research challenges. Computers and Electrical Engineering, 83, 106585.

[33] Stavrakas, V., and Flamos, A., 2020. A modular high-resolution demand-side management model to quantify benefits of demand-flexibility in the residential sector. Energy Conversion and Management, 205, 112339.

[34] Jonkeren, O., Francke, J., and Visser, J., 2019. A shift-share based tool for assessing the contribution of a modal shift to the decarbonisation of inland freight transport. European Transport Research Review, 11(1), 1-15.

[35] Capuder, T., Sprčić, D. M., Zoričić, D., and Pandžić, H., 2020. Review of challenges and assessment of electric vehicles integration policy goals: Integrated risk analysis approach. International Journal of Electrical Power and Energy Systems, 119, 105894.

[36] Jiehui Li, Yeyang Han, Gongping Mao and Ping Wang., 2020. Optimization of exhaust emissions from marine engine fueled with LNG/diesel using response surface methodology, Energy Sources, Part A: Recovery, Utilization, and Environmental Effects, 42:12, 1436-1448

[37] Ajanovic, A., Haas, R., 2019. Economic and environmental prospects for battery electric- and fuel cell vehicles: a review. Fuel Cell. 19 (5), 515529

[38] X. Shen, R. Fantacci and S. Chen., 2020. Internet of Vehicles [Scanning the Issue], in Proceedings of the IEEE, 108(2), pp. 242-245.

[39] Chugh, A., Jain, C., Mishra, V.P., 2020. IoT-based multifunctional smart toy car. Lecture Notes in Networks and Systems 103, 455-461.

[40] Padmaja, B., Rao, P. N., Bala, M. M., and Patro, E. K. R., 2018. A novel design of autonomous cars using IoT and visual features. In 2018 2nd International Conference on I-SMAC (IoT in Social, Mobile, Analytics and Cloud)(I-SMAC) ISMAC (IoT in Social, Mobile, Analytics and Cloud)(I-SMAC), 2018 2nd International Conference on (pp. 18-21). IEEE.

[41] Bylykbashi, K., Qafzezi, E., Ikeda, M., Matsuo, K., and Barolli, L., 2020. Fuzzy-based Driver Monitoring System (FDMS): Implementation of two intelligent FDMSs and a testbed for safe driving in VANETs. Future Generation Computer Systems, 105, 665-674.

[42] Abdou, M., Mohammed, R., Hosny, Z., Essam, M., Zaki, M., Hassan, M., and Mostafa, H., 2019. Endto-End Crash Avoidance Deep IoT-based Solution. In 2019 31st International Conference on Microelectronics (ICM) (pp. 103-107). IEEE.

[43] Luque-Vega, L. F., Michel-Torres, D. A., LopezNeri, E., Carlos-Mancilla, M. A., and GonzálezJiménez, L. E., 2020. Iot smart parking system based on the visual-aided smart vehicle presence sensor: SPIN-V. Sensors, 20(5), 1476.

[44] Perkovic, T., Solic, P., Zargariasl, H., Coko, D., Rodrigues, J.J.P.C., 2020. Smart parking sensors: state of the art and performance evaluation. J. Clean. Prod. 262, 121181. Volume 262.

[45] Saki, M., Abolhasan, M., and Lipman, J., 2019. A novel approach for big data classification and transportation in rail networks. IEEE Transactions on Intelligent Transportation Systems, 21(3), 12391249.

[46] H. F. Chong and D. W. K. Ng., 2017. Development of IoT device for traffic management system. Proc. - 14th IEEE Student Conf. Res. Dev. Adv. Technol. Humanity. 
[47] Kumar, H., Singh, M. K., Gupta, M. P., and Madaan, J., 2020. Moving towards smart cities: Solutions that lead to the Smart City Transformation Framework. Technological forecasting and social change, 153, 119281.

[48] Nižetić, S., Šolić, P., López-de-Ipiña González-deArtaza, D., and Patrono, L., 2020. Internet of Things (IoT): Opportunities, issues and challenges towards a smart and sustainable future. Journal of cleaner production, 274, 122877.

[49] Selvanathan, M., Hussin, N. A. M., and Azazi, N. A.N., 2020. Students learning experiences during COVID-19: Work from home period in Malaysian Higher Learning Institutions. Teaching Public Administration, 0144739420977900.

[50] Ahmed, E., Yaqoob, I., Gani, A., Imran, M., and Guizani, M., 2016. Internet-of-things-based smart environments: state of the art, taxonomy, and open research challenges. IEEE Wireless Communications, 23(5), 10-16.

[51] Syafrudin, M., Alfian, G., Fitriyani, N. L., and Rhee, J., 2018. Performance analysis of IoT-based sensor, big data processing, and machine learning model for real-time monitoring system in automotive manufacturing. Sensors, 18(9), 2946.

[52] Mehmood, Y., Ahmad, F., Yaqoob, I., Adnane, A., Imran, M., and Guizani, S., 2017. Internet-ofthings-based smart cities: Recent advances and challenges. IEEE Communications Magazine, 55(9), 16-24.

[53] Alam, T., 2021. Cloud-based IoT applications and their roles in smart cities. Smart Cities, 4(3), 11961219.

[54] Nikitas, A., Michalakopoulou, K., Njoya, E. T., and Karampatzakis, D., 2020. Artificial intelligence, transport and the smart city: Definitions and dimensions of a new mobility era. Sustainability, 12(7), 2789.

[55] Mishra, S., Patel, S., Panda, A. R. R., and Mishra, B. K., 2019. Exploring IoT-enabled smart transportation system. In The IoT and the Next Revolutions Automating the World (pp. 186-202). IGI Global.

[56] Tao, F., Qi, Q., Liu, A., and Kusiak, A., 2018. Data-driven smart manufacturing. Journal of Manufacturing Systems, 48, 157-169.

[57] Pereira, A. C., and Romero, F., 2017. A review of the meanings and the implications of the Industry 4.0 concept. Procedia Manufacturing, 13, 12061214.

[58] TechTarget., 2021. How Malaysia's industries are tapping IoT. Retrieved on $27^{\text {th }}$ December 2021 fromhttps://www.computerweekly.com/feature/Ho w-Malaysias-industries-are-tapping-IoT

[59] Ahmed, E., Yaqoob, I., Gani, A., Imran, M., and Guizani, M., 2016. Internet-of-things-based smart environments: state of the art, taxonomy, and open research challenges. IEEE Wireless Communications, 23(5), 10-16.

[60] Da Costa, C. A., Pasluosta, C. F., Eskofier, B., Da Silva, D. B., and da Rosa Righi, R., 2018. Internet of Health Things: Toward intelligent vital signs monitoring in hospital wards. Artificial intelligence in medicine, 89, 61-69.

[61] Ali, A., and Haseeb, M., 2019. Radio frequency identification (RFID) technology as a strategic tool towards higher performance of supply chain operations in textile and apparel industry of Malaysia. Uncertain Supply Chain Management, 7(2), 215-226.

[62] Moşteanu, N. R., 2021. Digital Campus-a future former investment in education for a sustainable society. In E3S Web of Conferences (Vol. 234, p. 00029). EDP Sciences.

[63] Kim, C. J., and Santiago, R., 2005. Construction of E-learning environments in Korea. Educational Technology Research and Development, 108-115.

[64] Sivakumar, D., Jusman, M. F. B., and Mastan, A. N. B. M., 2017. A case study review: Future of Internet of Things (IoT) in Malaysia. In ASCENT International Conference Proceedings-Information Systems and Engineering, 23-24, November 2017.

[65] Aldowah, H., Rehman, S. U., Ghazal, S., and Umar, I. N., 2017. Internet of Things in higher education: a study on future learning. In Journal of Physics: Conference Series (Vol. 892, No. 1, p. 012017). IOP Publishing.

[66] Selinger, M.; Sepulveda, A.; and Buchan, J., 2013. Education and the internet of everything. Cisco Consulting Services and Cisco EMEAR Education Team.

[67] Saiz-Rubio, V., and Rovira-Más, F., 2020. From smart farming towards agriculture 5.0: A review on crop data management. Agronomy, 10(2), 207.

[68] Kamilaris, A., Gao, F., Prenafeta-Boldu, F. X., and Ali, M. I., 2016. Agri-IoT: A semantic framework for Internet of Things-enabled smart farming applications. In 2016 IEEE 3rd World Forum on Internet of Things (WF-IoT) (pp. 442-447). IEEE.

[69] Koohafkan, P., Altieri, M. A., and Gimenez, E. H., 2012. Green agriculture: foundations for biodiverse, resilient and productive agricultural systems. International Journal of Agricultural Sustainability, 10(1), 61-75.

[70] Lim, S. B., Malek, J. A., Yussoff, M. F. Y. M., and Yigitcanlar, T., 2021. Understanding and Acceptance of Smart City Policies: Practitioners' Perspectives on the Malaysian Smart City Framework. Sustainability, 13(17), 9559.

[71] Majid, M. A. A., Abidin, I. H. Z., Majid, H. A. M. A., and Chik, C. T., 2015. Issues of halal food implementation in Malaysia. Journal of Applied Environmental and Biological Sciences, 5(6), 5056. 


\section{A Review of Internet of Things Application in Malaysia}

[72] Malek, J. A., Lim, S. B., and Palutturi, S., 2021. The ethics of smart city planning: Examining postutilitarianism in Malaysian blueprints. In 2021 International Conference on ICT for Smart Society (ICISS) (pp. 1-5). IEEE.

[73] Angelidou, M., 2014. Smart city policies: A spatial approach. Cities, 41, S3-S11.

[74] Kassim, R., 2021. Big Data for a Sustainable Smart City. Partridge Publishing Singapore.

[75] Omar, M. K., Zaman, M. D. K., and Yusoff, Y. M., 2020. Smart City-Green Intellectual Capital Model for Sustainability and a Higher Quality of Life. Global Business and Management Research, 12(4).

[76] Wang, S., Correia, G. H. D. A., and Lin, H. X., 2019). Exploring the performance of different ondemand transit services provided by a fleet of shared automated vehicles: An agent-based model. Journal of Advanced Transportation, 2019.

[77] Bedi, P., Goyal, S. B., Kumar, J., and Choudhary, S., 2022. Smart automobile health monitoring system. In Multimedia Technologies in the Internet of Things Environment, Volume 2 (pp. 127-146). Springer, Singapore.

[78] Sam, T. H., Wong, W. Y., Gwadabe, Z. L., Balakrishnan, R., Poopalaselvam, R., Adam, A., and Tee, K. S., 2021. The adoption of IoT technology in the Malaysian manufacturing industry. In AIP Conference Proceedings (Vol. 2355, No. 1, p. 030002). AIP Publishing LLC.

[79] Balan, E., Siddiq, M. S. B., and Khan, M. M., 2018.Economic Impact of Information Technology Outsourcing in Malaysia in the Era of IoT.

[80] Tiwari, S. T. S., Chan, S. W., Ahmad, M. F., and Zaman, I., 2019. Application and implementation of E-procurement technologies in Malaysian manufacturing firm. Int $\mathrm{J}$ Supply Chain Management, 8, 923.

[81] Munikrishnan, U. T., and Al Mamun, A., 2021. Survival and competitiveness of traditional travel agencies in Malaysia: a qualitative enquiry. International Journal of Culture, Tourism and Hospitality Research.

[82] Azlan, C. A., Wong, J. H. D., Tan, L. K., Huri, M. S. N. A., Ung, N. M., Pallath, V. and Ng, K. H.,2020. Teaching and learning of postgraduate medical physics using Internet-based e-learning during the COVID-19 pandemic-A case study from Malaysia. Physica Medica, 80, 10-16.

[83]Othman, M. R., 2021. Malaysia Seaport Development towards Embracing Industrial Revolution 4.0: Enhancing the Quality and Competitiveness of Seaport Industry. Turkish Journal of Computer and Mathematics Education (TURCOMAT), 12(3), 1625-1635.

[84] Rusuli, M. S. C., Halim, M. I. A., and Yaziz, M. F. A., 2021. Attitudes, Awareness, Readiness and Barriers Towards the Internet of Things Adoption
Among Construction Industry in East Cost Malaysia. Journal of Sustainable Management Studies eISSN 2773-5516, 2(1), 7-15.

[85] Chin, K. W., 2019. Technology Readiness of Local Contractors for Internet of Things Application at Construction Sites (Doctoral dissertation, Tunku Abdul Rahman University College).

[86] Yunus, E. N., 2020. The mark of industry 4.0: how managers respond to key revolutionary changes. International Journal of Productivity and Performance Management.

[87] Nagy, J., Oláh, J., Erdei, E., Máté, D., and Popp, J.,2018. The role and impact of Industry 4.0 and the internet of things on the business strategy of the value chain - the case of Hungary. Sustainability, 10(10), 3491.

[88] Ibrahim, F. S. B., Esa, M. B., and Kamal, E. B. M., 2019. Towards construction 4.0: Empowering bim skilled talents in malaysia. International Journal of Scientific and Technology Research, 8(10), 16941700.

[89] lot Tanko, B., and Mbugua, L., 2022. BIM Education in Higher Learning Institutions: A Scientometric Review and the Malaysia Perspective. International Journal of Built Environment and Sustainability, 9(1), 23-37.

[90] Suroso, A., Hendriarto, P., Mr, G. N. K.,Pattiasina, P. J., and Aslan, A., 2021. Challenges and opportunities towards Islamic cultured generation: socio-cultural analysis. Linguistics and Culture Review, 5(1), 180-194.

[91] Beschorner, N., 2021. The digital economy in the Southeast Asia: Emerging policy priorities and opportunities for regional collaboration1. New Dimensions of Connectivity in the Asia-Pacific, 121.

[92] Muhammad, Z., Hafez, M. A. A. M., Leh, N. A.M., Yusoff, Z. M., and Abd Hamid, S., 2020. Smart Agriculture Using Internet of Things with Raspberry Pi. In 2020 10th IEEE International Conference on Control System, Computing and Engineering (ICCSCE) (pp. 85-90). IEEE.

[93] Muangprathub, J., Boonnam, N., Kajornkasirat, S., Lekbangpong, N., Wanichsombat, A., and Nillaor, P., 2019. IoT and agriculture data analysis for smart farm. Computers and electronics in agriculture, 156, 467-474.

[94]Murali, K., and Sridhar, B., 2021. A smart Agriculture Irrigation System using sensor array based IOT. In Journal of Physics: Conference Series (Vol. 2062, No. 1, p. 012010). IOP Publishing.

[95] Munir, M. S., Bajwa, I. S., Ashraf, A., Anwar, W., and Rashid, R., 2021. Intelligent and Smart Irrigation System Using Edge Computing and IoT. Complexity. 
[96] Rehman, A., Saba, T., Kashif, M., Fati, S. M., Bahaj, S. A., and Choudhary, H., 2022. A Revisit of Internet of Things Technologies for Monitoring and Control Strategies in Smart Agriculture. Agronomy, 12(1), 127.

[97] Tao, W., Zhao, L., Wang, G., and Liang, R., 2021. Review of the internet of things communication technologies in smart agriculture and challenges. Computers and Electronics in Agriculture, 189, 106352.

[98] Aziz, D. A., Asgarnezhad, R., and Mahmood, S.N., 2021. The Recent Advances In IoT Based Smart Plant Irrigation Systems: A Brief Review. In 2021 5th International Symposium on Multidisciplinary Studies and Innovative Technologies (ISMSIT) (pp. 97-104). IEEE.
[99] Abba, S., Wadumi Namkusong, J., Lee, J. A., and Liz Crespo, M., 2019. Design and performance evaluation of a low-cost autonomous sensor interface for a smart iot-based irrigation monitoring and control system. Sensors, 19(17), 3643.

[100]Li, W., Awais, M., Ru, W., Shi, W., Ajmal, M.,Uddin, S., and Liu, C., 2020. Review of sensor network-based irrigation systems using IoT and remote sensing. Advances in Meteorology, 2020. 